\title{
MACUMBA EM ESCOLA PÚBLICA NO INTERIOR SERGIPANO TRANCA RUA VISITA ESCOLA DE ENSINO MÉDIO EM TEMPO INTEGRAL
}

\author{
MACUMBA IN PUBLIC SCHOOL IN THE SERGIPAN INTERIOR \\ TRANCA RUA GOES TO FULL-TIME HIGH SCHOOL
}

\section{MACUMBA EN ESCUELA PÚBLICA DEL INTERIOR SERGIPAN TRANCA RUA ASISTE A LA ESCUELA SECUNDARIA DE TIEMPO COMPLETO}

\author{
Jaime Rodrigues da Silva ${ }^{1}$ \\ Cláudia Regina Cardoso Rodrigues da Silva ${ }^{2}$ \\ Bárbara Regina Cardoso Rodrigues da Silva ${ }^{3}$
}

\begin{abstract}
RESUMO
A pesquisa foi construída após a contestação que um grupo de alunos, praticantes do culto afro-brasileiro da Umbanda e do Candomblé, fizeram sobre a discriminação que sofriam em uma escola pública de EMTI no interior sergipano, após a implantação de um "Clube de Protagonismo", intitulado "Clube da Bíblia". Ocorre que a escola, apesar de ser um ambiente democrático e plural, não deve estimular a propagação de manifestações de uma ou outra religião, visto que a opção do país é de ser um Estado Laico (art. $5^{\circ}$ da Constituição Federal de 1988, inciso VI). Nesse sentido, apresentamos a comunidade escolar o "Sr. Tranca Rua", "entidade/divindade" tantas vezes marginalizada e erroneamente associada ao diabo pelos neopentecostais. Para facilitar a abordagem dos fatos e a sua análise, utilizamos Foucault (1979; 2005), Caputo (2012) e Bogdan e Biklen (1994). Perseguimos dois objetivos: o de levar para a comunidade escolar a oportunidade de conhecer - pela ótica não dominante - alguns "atores" do culto afro-brasileiro, como "Tranca Rua"; propor a reflexão da necessidade de se discutir sobre a inclusão/exclusão de seres humanos, que precisaram negar a sua crença religiosa para serem aceitos, tolerados ou ignorados por um grupo social majoritário. Iniciamos a pesquisa com a coleta das impressões que os estudantes traziam de suas interações com a divindade intitulada como "Sr. Tranca Rua". Após a coleta e análise (abordagem qualitativa), propomos uma pesquisa bibliográfica. Apresentamos o filme Besouro e fizemos diversos encontros para estimular a oralidade dos estudantes. Novas problemáticas surgiram nos encontros, mostrando a necessidade de continuar pesquisando sobre o assunto.
\end{abstract}

PALAVRAS-CHAVE: Exu e Tranca Rua. Clube de Protagonismo. Umbanda e Candomblé. Pesquisa bibliográfica.

Submetido em: 20/12/2020 - Aceito em: 03/03/2021 - Publicado em: 12/07/2021

${ }^{1}$ Professor de Química e Física na Secretaria de Educação de Sergipe/Alagoas; Mestre em Ensino de Ciências e Matemática; Bacharelando em Direito; Umbandista. Orcid: https://orcid.org/0000-0002-9958-7846. E-mail: profjaimersilva@gmail.com. ${ }^{2}$ Professora de Educação Física na Secretaria de Educação de Alagoas; Bacharelanda em Fisioterapia; Umbandista.

${ }^{3}$ Bacharelanda em Direito; Umbandista. 


\begin{abstract}
The research was built after the challenge that a group of students, practitioners of the Afro-Brazilian cult of Umbanda and Candomblé, made about the discrimination they suffered in a public school of EMTI in the interior of Sergipe, after the implantation of a "Protagonism Club" ", Entitled" Clube da Bíblia ".It happens that the school, despite being a democratic and plural environment, should not stimulate the spread of manifestations of one or another religion, since the country's option is to be a Secular State (art. 5 of the 1988 Federal Constitution, item SAW). In this sense, we introduce the school community to "Mr. Tranca Rua ", " entity / divinity "so often marginalized and wrongly associated with the devil by the neo-Pentecostals. To facilitate the approach to the facts and their analysis, we used Foucault (1979; 2005), Caputo (2012) and Bogdan and Biklen (1994). We pursue two goals: to bring the school community the opportunity to meet - from a non-dominant perspective - some "actors" of the Afro-Brazilian cult, such as "Tranca Rua"; to propose a reflection on the need to discuss the inclusion / exclusion of human beings, who had to deny their religious belief in order to be accepted, tolerated or ignored by a majority social group. We started the research by collecting the impressions that students brought from their interactions with the deity entitled "Mr. Lock Street". After collection and analysis (qualitative approach), we propose a bibliographic search. We presented the film Besouro and held several meetings to encourage students to speak. New problems arose at the meetings, showing the need to continue researching on the subject.
\end{abstract}

KEYWORDS: Exu and Tranca Rua. Protagonism Club. Umbanda and Candomblé. Bibliographic research

\title{
RESUMEN
}

La investigación se construyó por el desafío que un grupo de estudiantes, practicantes del culto afrobrasileño de Umbanda y Candomblé, hicieron sobre la discriminación que sufrieron en una escuela pública de EMTI en el interior de Sergipe, luego de la implantación de un "Club de Protagonismo". , titulado "Club de la Biblia". Ocurre que la escuela, a pesar de ser un ambiente democrático y plural, no debe estimular la difusión de manifestaciones de una u otra religión, ya que la opción del país es ser un Estado laico (art. 5 de la Constitución Federal de 1988, inciso SIERRA). En este sentido, presentamos a la comunidad escolar al "Sr. Tranca Rua ", " entidad / divinidad "tantas veces marginada y erróneamente asociada con el diablo por los neopentecostales. Para facilitar el acercamiento a los hechos y su análisis, utilizamos a Foucault (1979; 2005), Caputo (2012) y Bogdan y Biklen (1994). Buscamos dos objetivos: brindar a la comunidad escolar la oportunidad de conocer, desde una perspectiva no dominante, algunos "actores" del culto afrobrasileño, como "Tranca Rua"; proponer una reflexión sobre la necesidad de discutir la inclusión / exclusión del ser humano, que tuvo que negar su creencia religiosa para ser aceptado, tolerado o ignorado por un grupo social mayoritario. Comenzamos la investigación recopilando las impresiones que los estudiantes trajeron de sus interacciones con la deidad titulada "Sr. Lock Street ". Después de la recolección y análisis (enfoque cualitativo), proponemos una búsqueda bibliográfica. Presentamos la película Besouro y celebramos varias reuniones para animar a los estudiantes a hablar. En las reuniones surgieron nuevos problemas que evidenciaron la necesidad de seguir investigando sobre el tema.

PALABRAS CLAVE: Exu y Tranca Rua. Club de protagonismo. Umbanda y Candomblé. Investigación bibliográfica

\section{INTRODUÇÃO}

O trabalho de pesquisa desenvolvido teve dois objetivos: o primeiro foi de levar para a comunidade escolar a oportunidade de conhecer - pela ótica não dominante - alguns "atores" do culto afro-brasileiro, como "Tranca Rua do Embaré" e "Tranca Rua das Almas", por exemplo; o segundo foi de propor a reflexão da necessidade de se discutir sobre a inclusão/exclusão de seres humanos, sejam negros, brancos, mestiços, indígenas, entre outros, que ao longo do tempo precisaram negar a sua crença religiosa, para serem aceitos, tolerados ou ignorados por um grupo social majoritário. Portanto, essas problemáticas que encontramos no cotidiano escolar justificam a execução da pesquisa, pois trazem para o ambiente plural da escola discussões essenciais para o convívio de professores e estudantes, mas também 


\section{Revista Docência e Cibercultura}

convidam a comunidade para uma reflexão sobre como agir com aqueles atores apontados como "diferentes".

A escola pública em que ocorreu a pesquisa segue a proposta de Ensino Médio em Tempo Integral (EMTI), defendida pela Secretaria de Educação de Sergipe, a partir do Modelo da Escola da Escolha de Pernambuco, então baseado em três eixos: formação acadêmica de excelência, formação para a vida e formação para o desenvolvimento das competências do século XXI. É importante destacar, que o modelo pedagógico da Escola da Escolha é estruturado segundo quatro pilares da educação, ou seja, o aprender a conhecer; o aprender a fazer; o aprender a conviver; o aprender a ser (ICE, 2010, p.12).

O Instituto de Corresponsabilidade pela Educação (ICE) descreve, no Manual Operacional do ICE (2010, p. 11), as diretrizes da "Escola da Escolha". Destaca-se a metodologia de êxito que funciona por meio de procedimentos teórico-metodológicos, buscando favorecer a experimentação de atividades dinâmicas, contextualizadas e significativas nos campos das ciências, artes, linguagens e cultura corporal. Nesse sentido, os componentes curriculares são organizados através do "Projeto de Vida", das "Práticas e Vivências em Protagonismo", das "Disciplinas Eletivas" e do "Estudo Orientado".

As Práticas e Vivências em Protagonismo são as atividades promovidas pela escola, pelas instituições parceiras ou pelos próprios estudantes. O objetivo é desenvolver valores e competências pessoais e sociais, bem como ampliar o repertório de conhecimento para contribuir no processo de formação de um ser humano autônomo, solidário e competente. Um exemplo de Prática e Vivência em Protagonismo, que se destaca é o "Clube de Protagonismo" (ICE, 2010, p.15).

A presente pesquisa traz para reflexão a problemática que envolveu a construção de um "Clube de Protagonismo", intitulado "Clube da Bíblia", em uma escola pública de EMTI no interior sergipano. Ocorre que a escola, apesar de ser um ambiente democrático e plural, não deveria estimular a propagação de manifestações de uma ou outra religião, visto que a opção do país é de ser um Estado Laico, segundo descreve o art. $5^{\circ}$ da Constituição Federal de 1988, inciso VI (BRASIL, 1998, p. 18). Por isso, defendemos que a inserção no ambiente escolar de ensinamentos baseados em um suposto "livro sagrado" - bíblia, de católicos e protestantes referenda a mensagem, mesmo de forma subjetiva, de que tudo aquilo que não se encontra na "escritura sagrada" (bíblia) é profano, pagão e deve, como tal, ser abolido e ou discriminado e ou desprezado. Nesse sentido, concordamos com Caputo (2009, p. 1), "se Jesus pode entrar na escola, por que Exu não pode"? E, convocamos os indivíduos a ponderarem e refletirem sobre suas práticas, apresentando a possibilidade de discutir aspectos de outras religiões, principalmente, o Candomblé e a Umbanda . 
Em contrapartida um grupo de professores, com opção religiosa evangélica-neopentecostal, utilizando o argumento do respeito a escolha do estudante na construção do "Clube de Protagonismo", estimularam encontros, fizeram doações de bíblias e promoveram a fé cristãevangélica como caminho para a "salvação", inclusive defendendo a suposta "cura-gay”. E, por isso resolvemos nos manifestar, pois o fato tornou-se ainda mais grave, quando um professor durante as aulas tinha o costume de propor a leitura e à reflexão de "passagens bíblicas", seja antes de iniciar o conteúdo ou no fim da aula, após a chamada nominal. Nessa prática, o docente deixou claro que todos os alunos deviam estar presentes, independente da opção religiosa. Observou-se, claramente, a relação de poder daquele que supostamente detém o conhecimento, para com os que absorvem esses ensinamentos. Concordamos com Foucault (1979, p. 45), de que não há relação de poder sem constituição de um campo de saber, como também, reciprocamente, todo saber constitui novas relações de poder.

Destacamos, que a atitude do professor está em desacordo com a Lei de Diretrizes e Bases da Educação Nacional (LDB - lei $\mathrm{n}^{0} 9.394 / 1996$ ), que no art. $3^{0}$, incisos III e IV reafirmam o compromisso sobre os princípios do "pluralismo de ideias e de concepções pedagógicas" e do "respeito à liberdade e apreço à tolerância. Contudo, indignados com os fatos descritos, um grupo minoritário de meninas e meninos, praticantes do culto afro-brasileiro do Candomblé e da Umbanda, alguns declaradamente homossexuais, por se sentirem discriminados e ofendidos na sua crença, se negaram a continuar sendo apontados como "adoradores do diabo", "macumbeiros" e ou "xangôzeiros", seja pelo dito professor ou seus "seguidores". No fim de uma das aulas, os estudantes buscaram reparação com a coordenação pedagógica. Nesse sentido, exaltamos as contribuições de Foucault (1979, p. 45) que, ao escrever sobre poder e saber, estava certo.

Não obstante, para estimular a prática do "aprender a conhecer", do "aprender a fazer", do "aprender a conviver" e do "aprender a ser" - os quatro pilares da educação integral - aplicamos os ensinamentos de Foucault (1979, p. 45) e apresentamos a comunidade escolar o "Sr. Tranca Rua", "entidade/divindade" tantas vezes marginalizada e erroneamente associada ao diabo pelos adeptos do cristianismo, em especial os neopentecostais.

\section{ASPECTOS METODOLÓGICOS}

Iniciamos a pesquisa com a coleta das impressões que um grupo de estudantes da escola de EMTI, praticantes do culto afro-brasileiro do Candomblé e da Umbanda, traziam de suas interações com a divindade intitulada como "Sr. Tranca Rua". Foram propostas três questões subjetivas e analisadas segundo Bogdan e Biklen (1994, p. 39).

Após a coleta e análise das respostas (abordagem qualitativa), seguimos com uma pesquisa bibliográfica para levantar, entre pesquisadores e estudantes, a visão científica destas práticas 
religiosas, como também das construções históricas e sociais advindas do desenvolvimento do culto afro no Brasil ao longo do tempo. O intuito foi apresentar aos estudantes que o conhecimento que eles traziam de seus ancestrais, apesar de marginalizado e desprezado no local, inclusive na escola, era reconhecido, legitimado, respeitado e estudado pela academia. Portanto, não deveria ser "escondido".

Em conjunto com a pesquisa bibliográfica apresentamos o filme "Besouro" e promovemos a discussão sobre alguns aspectos da figura de Exu, que no filme é bastante eloquente. Além disso, aspectos que envolvem a Capoeira, como a marginalização da prática e o uso como forma de resistência cultural, foram apresentados e refletidos, pois são pontos que acreditamos serem relevantes e podem ser explorados em outra (s) pesquisa (s).

Como atividade final foi proposta uma exposição, com os resultados obtidos da pesquisa e a construção de materiais informativos em folders, poldcast, cartazes, entre outros, para discutir e informar sobre aspectos da Umbanda e do Candomblé, visto que a comunidade tem origem em um Quilombo. No entanto, por conta da Pandemia do Covid-19 não foi possível acontecer.

As reflexões apresentadas aos estudantes, seguiram com as solicitações do cargo que possuem no terreiro e o tempo que permanecem no culto:

a) você conhece a divindade intitulada "Sr. Tranca Rua"? Se a resposta for sim, descreva, resumidamente, como este se apresenta no terreiro que você frequenta ("qualidade ou sobrenome", como por exemplo: "Tranca Rua das Almas"; vestimenta ou qualquer outro aspecto que acredite ser relevante);

b) para você Tranca Rua e Exu representam a mesma "entidade/divindade"? Explique, resumidamente;

c) descreva, resumidamente, qual o significado dos Exus dentro do contexto da sua prática religiosa.

Os questionamentos buscam entender qual o grau de conhecimento dos estudantes sobre Exu e "Tranca Rua". Escolhemos o Orixá Exu e a "divindade" "Tranca Rua", por estarem mais difundidas nas mídias sociais e serem alvos constantes de ataques do cristianismo, seja católico ou neopentecostal, em decorrência do posicionamento equivocado de líderes religiosos e ou frequentadores. 


\section{RESULTADOS E DISCUSSÃO}

Aceitaram participar da pesquisa seis estudantes, sendo cinco meninos e uma menina. Ocorre que um dos meninos, por ter iniciado no "Culto dos Orixás" a três semanas, resolveu contribuir somente respondendo a primeira pergunta. Concordamos com a atitude e defendemos a participação espontânea.

Para facilitar o tratamento dos dados os estudantes foram identificados pela letra maiúscula $\mathrm{S}$, de sujeito, seguido de um algarismo (número) arábico. Sendo assim, o primeiro sujeito foi representado por S1, o segundo por S2 e assim, sucessivamente.

Para a análise dos fragmentos utilizamos Bogdan e Biklen (1994, p. 31), visto que esses autores criaram um método que facilita interpretar dados que envolvem a descrição de pessoas, objetos, lugares, atividades, acontecimentos e conversas. Além disso, encontramos em Geertz (2008, p. 20) sustentação para refletir sobre as descrições e narrativas, os símbolos e as expressões, como também os ambientes da cultura e das condutas do grupo social pesquisado.

Revisitamos, nessa perspectiva, Foucault (2005, p. 11) sobre os "saberes sujeitados". Saberes estes, que apesar de estarem a nossa volta e de serem construídos ao longo do tempo, são ocultados, desqualificados e por vezes não entram na ótica "do dizível”, mas que podem ser apresentados como ferramentas de discussão e reflexão em diferentes focos de interesse, como de raça, etnia, gênero, por exemplo. Sobre as vivências destes adolescentes com a Umbanda e o Candomblé, em seus terreiros, concordamos com Caputo (2012, p. 74), ao afirmar que ocorrem inúmeras práticas ritualísticas que influenciam nos modos como os sujeitos se colocam no mundo.

A afirmativa de Caputo (2012, p. 74) ganha mais significado quando analisamos o quadro 1, que demonstra a identificação dos sujeitos, suas funções ou cargos (atribuições) no terreiro, o tempo de permanência no culto e orixá responsável, que foi escolha dos estudantes em mencionar.

É preciso esclarecer que a atuação dos estudantes, em contestar a forma discriminatória com que eram tratados, aponta para a necessidade da escola - como instituição educativa - em ouvir e permitir que esses atores tenham voz e possam contestar o poder hegemônico constituído. Foi possível observar que os indivíduos que exercem liderança em seus terreiros conseguiram se organizar mais facilmente, resistindo ao poder imposto e se colocando de forma a contestar a visão de mundo do professor (FOUCAULT, 1979; CAPUTO, 2012). E, assim, concordamos com Caputo (2012, p. 251-252) ao revisitar a definição de multiculturalismo revolucionário de McLaren (2000, p. 284) que aprofunda a crítica a sociedade discriminatória. Mas, também destacamos a perspectiva intercultural trazida por Candau (2008, p. 23), que defende: 
[...] uma educação para o reconhecimento do "outro", para o diálogo entre os diferentes grupos sociais e culturais. Uma educação para a negociação cultural que enfrenta os conflitos provocados pela assimetria de poder entre diferentes grupos socioculturais nas nossas sociedades e é capaz de favorecer a construção de um projeto comum, pelo qual as diferenças sejam dialeticamente incluídas.

E nesta perspectiva de caminhar para um tipo de educação que valorize o outro, mesmo este não sendo membro de um grupo hegemônico, apresentamos o Quadro 1 que resume um pouco da diversidade cultural que pode ser explorada com esses estudantes presentes na escola.

Quadro 1. Caracterização do grupo de alunos e suas identificações no culto afro-brasileiro

\begin{tabular}{|c|c|c|c|}
\hline Sujeito & Cargo & Tempo de Culto & Orixás "responsáveis" \\
\hline S-1 & Babalorixá & 7 anos & Oxum/Oxóssi \\
\hline S-2 & Ogã & 10 anos & Nanã/Obaluaê \\
\hline S-3 & Ekedi & 7 anos & Oxum/Xangô \\
\hline S-4 & Médium "Rodante" & 13 anos & Iansã/Ogum \\
\hline S-5 & Ogã & 12 anos & Yemanjá/Xangô \\
\hline S-6 & Médium "Rodante" & 3 semanas & Iansã/Omolu \\
\hline
\end{tabular}

Fonte: autores (2020)

A identificação do grupo permitiu concluir que apesar da pouca idade (menores de 19 anos), os indivíduos possuem cargos de destaque dentro da hierarquia do culto e tiveram a iniciação ainda crianças. O que não é surpreendente, como destacou Caputo (2012, p. 66) ao descrever que "as crianças de Candomblé desempenham funções como adultos".

A maioria é praticante do Candomblé, com exceção de S-4 que frequenta a Umbanda. Os sujeitos S-1, S-3, S-5 e S-6 pertencem ao mesmo "barracão" e fazem questão de identificar S1, como "Pai de Santo". S-2, se relaciona com todos os outros em harmonia, inclusive "pedindo e dando a bênção", mesmo sendo de outro terreiro de Candomblé.

S-4, por ser filho de uma "Mãe de Santo" muita conhecida na cidade, dispõe de um certo prestígio e também desperta desprezo de alguns. Como bom "filho de Ogun", faz sucesso com as meninas. S-4 afirma que na "Casa de Umbanda de sua Mãe" ele será o dirigente, pois Iansã assim deseja e sua mãe também, apesar de dizer que sonha estudar para ser engenheiro e teme que a religião possa dificultar essa condição.

Analisando as características descritas no quadro 1 foi possível entender o motivo que levou os alunos a procurarem a coordenação pedagógica, para exporem a sua insatisfação com a postura 
do professor. Para eles, o culto ao orixá faz parte de sua identidade. E, portanto, levar a figura de Exu e do "Sr. Tranca Rua" para esse campo de conflito foi bem aceito por eles.

Quando iniciamos a pesquisa com a coleta das impressões que os estudantes traziam de suas interações com a divindade "Sr. Tranca Rua", solicitamos a indicação do cargo, do tempo que praticavam o culto e da possibilidade em apontar os Orixás que "carregavam". Assim fizemos, com o intuito de buscar entender como os sujeitos descreviam o contexto e argumentavam sobre o tema.

A pergunta "a" - você conhece a "divindade" intitulada "Sr. Tranca Rua"? Se a resposta for sim, descreva, resumidamente, como este se apresenta no terreiro que você frequenta ("qualidade ou sobrenome", como por exemplo, "Tranca Rua das Almas"; vestimenta ou qualquer outro aspecto que acredite ser relevante) - foi respondida por todos os sujeitos e o resultado foi surpreendente. Não houve um aluno que não apontasse a "entidade" como parte integrante do culto e até (entusiasmados) comentaram de suas experiências com os "exus" em seus terreiros. No fim acabei sendo estimulado a contar algumas experiências que tive com "Tranca Rua".

Quadro 2. Respostas referentes a pergunta "a"

\begin{tabular}{|c|l|}
\hline Sujeitos & \multicolumn{1}{c|}{ Respostas Fornecidas ao item "a" } \\
\hline S-1 & $\begin{array}{l}\text { Sim. "Tranca Rua" é frequentador do nosso terreiro... Ele se apresenta como } \\
\text { "Tranca Rua das Sete Encruzilhadas". Veste capa preta, usa cartola e bengala. É } \\
\text { bastante sério, bebe cachaça pura, fuma charuto e quando conversa explica tudo } \\
\text { bem devagar... }\end{array}$ \\
\hline $\begin{array}{c}\text { S-2 } \\
\text { Ogã }\end{array}$ & $\begin{array}{l}\text { Sim. O Pai de Santo é "cavalo" de "Tranca Rua". Ele se apresenta como "Tranca } \\
\text { Rua das Almas". Veste capa preta, usa cartola preta e vermelha, fuma charuto e } \\
\text { "toma" bebidas fortes. É muito sério e transmite força. Gosto muito dele. }\end{array}$ \\
\hline $\begin{array}{c}\text { S-3 } \\
\text { Ekedi }\end{array}$ & $\begin{array}{l}\text { Sim. Conheço Tranca Rua. Ele tem um médium em nossa "Casa de Santo". Meu } \\
\text { pai e meu irmão carnais, que não frequentam mais terreiro, "viravam" com ele. } \\
\text { Lembro bem, usava calça preta e capa, mas sem camisa. Não sei, com certeza. Acho } \\
\text { que era Tranca Rua das Almas. }\end{array}$ \\
\hline $\begin{array}{c}\text { S-4 } \\
\text { "Rédium }\end{array}$ & $\begin{array}{l}\text { Sim. "Tranca Rua" é frequentador do nosso terreiro... Minha mãe "carrega Tranca } \\
\text { Rua das Almas", que também é meu exu. Veste capa preta, cartola e da "consulta". } \\
\text { Eu trabalho com Tranca Rua e minha mãe também. Ele é forte, minha mãe fica } \\
\text { cansada. }\end{array}$ \\
\hline $\begin{array}{l}\text { Sim.5 "Tranca Rua" frequenta nosso Ilê. Acho que é o "Tranca Rua das Sete } \\
\text { Ogã }\end{array}$ & $\begin{array}{l}\text { Encruzilhadas". Usa capa preta, cartola e às vezes bengala. Quase não fala. Bebe } \\
\text { cachaça, fuma vários charutos e dá "consulta" }\end{array}$ \\
\hline
\end{tabular}


Revista Docência e Cibercultura

\begin{tabular}{|c|l|}
\hline S-6 & $\begin{array}{l}\text { Sim. No terreiro tem um "Tranca Rua". Não sei o "nome completo", nem "vi” nas } \\
\text { "giras". Minha Vó, por parte de pai, recebia o Sr. Tranca Rua do Imbaré. Ele vestia } \\
\text { Médium } \\
\text { uma capa preta, com fundo vermelho. A cartola era preta com uma faixa vermelha. } \\
\text { Bebia cachaça, fumava charuto, conversava devagar e ria sempre que me via. Eu } \\
\text { era pequeno, mas lembro muito bem da fila de pessoas as segundas-feiras. }\end{array}$ \\
\hline
\end{tabular}

Fonte: autores (2020)

Os sujeitos S-1, S-3, S-5 e S-6, que pertencem ao mesmo "barracão", sendo S-1 o dirigente, possuem um modo diferente de definir a "entidade". Para S-3, que tem o "cargo de "Ekedi" pessoa encarregada de preparar as oferendas dos Orixás - "Tranca Rua das Almas" era quem "acompanhava" seu pai e irmão, o que fez com que ela descrevesse a "divindade" em detrimento daquela que é parte de seu terreiro. Nota-se, portanto, uma relação de proximidade, de zelo e respeito, como se houvesse uma "espécie" de laço familiar e espiritual que os une, apesar do irmão e do pai não frequentarem mais a religião.

A mesma sensação de pertencimento foi percebida na explicação de S-6, que não descreveu o "Tranca Rua das Sete Encruzilhadas" de seu terreiro, mas fez questão de escrever sobre o "Tranca Rua do Imbaré" de sua Vó. Uma narrativa carregada de simbolismo, com riqueza de detalhes e que permite identificar o seu grupo social e possibilita afirmar que "Tranca Rua" gera cultura, que passa de geração para geração e que resiste e encanta, apesar dos constantes ataques que sofre. Nesse sentido, a diversidade que o culto afro-brasileiro carrega precisa ser mais trabalhado nas escolas.

Apesar da implantação da Lei 10.639/2003, que instituiu a obrigatoriedade do ensino de História e Cultura Africana e Afro-Brasileira nos currículos da Educação Básica no Brasil, pouco se tem feito para garantir a sua expansão nos planejamentos. As atividades que envolvem a problemática, na sua maioria, são limitadas a semana de comemoração da "Consciência Negra".

A Lei 10.639/2003 trouxe avanços importantes, pois questiona o currículo oficial e propõe reflexões sobre o que ensinar nas escolas, permitindo que haja reconhecimento e valorização da identidade afro e sua importância na formação da sociedade brasileira. Conforme provoca Santos (2001, p. 20), "a tarefa da escola é fazer com que a História seja contada por mais vozes, para que o futuro seja escrito por mais mãos".

No aspecto da Lei 10.639/2003, as narrativas de S-2 e S-4 se tornam mais especiais e tem um cunho político-cultural inquestionável. S-2, que é "Ogã" - pessoa com a responsabilidade de tocar os atabaques e participar das cerimônias de iniciação - descreve que o "Tranca Rua das Almas" de seu "Pai de Santo" - dirigente do terreiro, "Babalorixá" ou "Babá" ou "Zelador de Santo" - é muito sério e transmite força. Esta afirmação possui semelhanças com a narrativa 


\section{Revista Docência e Cibercultura}

de S-4, "Médium "Rodante" - indivíduo que "recebe ou incorpora" a "entidade" - que afirma que o Tranca Rua frequentador do terreiro é "forte e deixa sua mãe cansada".

Entendemos, que as narrativas demonstram mais do que aspectos do cotidiano, exprimem sentimentos dos (as) participantes e reiteram a ideia de que os terreiros são instituições culturais, muitas vezes conduzidos por pessoas que agem como mediadores (as) culturais (Caputo, 2012, p. 262).

O questionamento proposto na pergunta "b" - para você Tranca Rua e Exu representam a mesma "entidade/divindade"? Explique, resumidamente - trouxe uma inquietude. Para todos, sem exceção, "Tranca Rua" e o Orixá Exu são a "mesma coisa" (S-1). Não houve distinção entre o Orixá Exu e o "encantado Tranca Rua". Nesse sentido, apesar de concordarmos que se trata de uma tarefa difícil definir os personagens, buscamos algumas interpretações trazidas por Prandi (2001, p. 23) e Da Costa (1980, p. 18), na tentativa de explicar Exu:

1) [...] "é o santo ou orixá que os africanos têm grande tendência a confundir com o diabo. No entanto, sou levado a crer que esta identificação é apenas o produto de uma influência do ensino católico" [..] (RODRIGUES e VELHO, 2006, p. 39-40);

2) [...] "Exu é outro "orixá". É o representante das potências contrárias ao homem. Os afrobaianos assimilam-no ao demônio dos católicos; mas, o que e interessante, temem-no, respeitam-no fazendo dele objeto de culto". [...] "Exu, orixá malfazejo, tornou-se o diabo dos católicos, na Bahia como no Rio de Janeiro" (RAMOS, 1951, p. 40);

3) [...] "I - Exu-orixá, da mesma natureza que todos os outros, com suas histórias e suas aventuras como Oxalá e Iemanjá"; "II - Exu-alma dos suicidas ou assassinados. São estes Exus fantasmas lívidos, que aparecem durante a noite e percorrem a terra assustando os vivos"; "III - Exu-espécie de anjo-da-guarda, baseado nas informações que "todos possuem um Exu e vários Ibeji, além do orixá que pode nos visitar"; "IV - Exu-acompanhante de todo orixá, fundado em que "todo orixá tem o seu Exu'", isto é, todo orixá tem seu Elegba. Neste nível, Exu seria "uma força mística escondida, uma espécie de fragmentação e de individualização do mana disperso pelo Universo" (BASTIDE, 1945, p. 132-134).

Neste espectro revisitamos a Ialorixá Elizabeth de Oxum Opará, "Mãe de Santo" do Ilê Lebará Cigana de Nilópolis-RJ, ao afirmar que existem dois tipos de Exu: o Coroado e o Batizado. Exu Coroado seria o Orixá, que não teve corpo físico e que coexiste na natureza e na devoção dos seres humanos, como Oxalá, Nanã, Oxum, Ogun, Oxóssi, Yansã, Xangô, Obaluaê e Iemanjá, dentre outros. O segundo, Exu Batizado, seria aquela energia oriunda do astral que possui um certo grau de evolução, que por merecimento transita entre os seres humanos contribuindo em 
seu processo de aprimoramento espiritual, portanto, este já possuiu corpo físico. Fazem parte deste grupo Tranca Rua, Maria Padilha, Marabô, Mulambo, entre tantos outros.

Estas tentativas de definir e diferenciar Exu e Tranca Rua foram apresentadas ao grupo, mas buscou-se deixar claro que a definição não é completa, não está pronta e nem deve ser considerada um ato final, pois se modifica segundo variam os aspectos culturais e sociais do local. Exu no Rio de Janeiro, apesar de semelhanças com o culto na Bahia, por exemplo, possui algumas particularidades inerentes ao sacerdote ou "Pai de Santo" que conduz o terreiro e são trazidas ou não de seus antepassados. E isso que é extraordinário, não existe dois "Tranca Ruas" iguais, mesmo com vestimenta e designações semelhantes.

São estes mistérios que fazem o culto da Umbanda e do Candomblé algo complicado de ser descrito por uma espécie de "bíblia", pois cada "Casa de Orixá" tem a sua própria "bíblia sagrada". Esta diversidade de signos e significados precisa ser apresentada, sem preconceito e sem pudor, pois a escola é um espaço de construção de conhecimentos e de desenvolvimento de valores, podendo contribuir para a transformação da sociedade tornando-a menos desigual e mais democrática.

No intuito de dialogar com a perspectiva de valorização da diversidade e sua utilização no currículo, segundo propõe a Lei 10.639/2003, trazemos Paulo Freire para o contexto da pesquisa. Sabemos, que a prática libertadora proposta pelo educador permite interligar pensamento e ação, pois enquanto o homem regula e reorienta sua ação poderá concordar ou discordar sobre algo. Sendo assim, para Freire (2003, p. 28) ninguém é melhor que os oprimidos/excluídos para lutarem contra a opressão/exclusão, visto que eles sentiram na pele tal realidade. Em contrapartida:

[...] quem, melhor que os oprimidos, se encontrará preparado para entender o significado terrível da sociedade opressora? Quem sentirá, melhor que eles, os efeitos da opressão? Quem, mais que eles, para ir compreendendo a necessidade de libertação? Libertação à qual não chegaram pelo acaso, mas pela práxis de sua busca; pelo conhecimento e reconhecimento da necessidade de lutar por ela (FREIRE, 2003, p. 30).

E nesta reflexão trazida por Freire (2003, p. 30), seguimos para a análise da última pergunta que foi identificada pela letra "c" - descreva, resumidamente, qual o significado dos Exus dentro do contexto da sua prática religiosa - e deixou claro que para o grupo de estudantes, independente do cargo que possuem dentro do culto dos Orixás, Exu tem um significado especial. Para eles não se faz nada dentro do Candomblé ou na Umbanda para se conectar a um Orixá, seja ele qual for, sem antes "arriar" uma oferenda para Exu”. Para S-1 e seus seguidores, Exu é quem “come primeiro e ri por último". E é verdade. 
O quadro 03 apresenta as respostas dos estudantes.

Quadro 3. Respostas referentes a pergunta "c"

\begin{tabular}{|c|l|}
\hline Sujeitos & \multicolumn{1}{c|}{ Respostas Fornecidas ao item "c" } \\
\hline S-1 & $\begin{array}{l}\text { Exu é quem "come primeiro e ri por último". Sem Exu não se chega ao Orixá. Eles } \\
\text { (os Orixás) têm uma espécie de pacto, não "comem nada, sem Exu comer antes". } \\
\text { Na minha casa Exu sempre é respeitado. }\end{array}$ \\
\hline $\begin{array}{c}\text { S-2 } \\
\text { Ogã }\end{array}$ & $\begin{array}{l}\text { Exu é força, união, celebração. Exu traz para quem merece e retira daquele que } \\
\text { deve. Quando Exu "pisa" no terreiro é uma mistura de medo e alegria. }\end{array}$ \\
\hline $\begin{array}{c}\text { S-3 } \\
\text { Ekedi }\end{array}$ & $\begin{array}{l}\text { Para Exu eu cozinho satisfeita. Exu é simples, mas as comidas precisam ser } \\
\text { preparadas com amor. O silêncio no barracão é necessário. }\end{array}$ \\
\hline $\begin{array}{c}\text { S-4 } \\
\text { Médium } \\
\text { "Rodante" }\end{array}$ & $\begin{array}{l}\text { Exu na minha pratica religiosa é a ligação entre os homens e os Orixás. Exu sabe o } \\
\text { assim ensina minha mãe e ensinou meu avô. }\end{array}$ \\
\hline $\begin{array}{c}\text { S-5 } \\
\text { Ogã }\end{array}$ & $\begin{array}{l}\text { Exu é o início de tudo que fazemos dentro do culto. Exu é quem responde no jogo } \\
\text { de búzios, quem dá consulta, quem recebe oferenda e quem ajuda os clientes. Eu } \\
\text { "toco" para Exu satisfeito. }\end{array}$ \\
\hline $\begin{array}{c}\text { S-6 } \\
\text { Médium } \\
\text { "Rodante" }\end{array}$ & \begin{tabular}{l} 
Não respondeu. \\
\hline
\end{tabular} \\
\hline
\end{tabular}

Fonte: autores (2020)

Com a construção da pergunta "c" esperávamos receber as informações de como a "divindade Tranca Rua" estava relacionada com o dia a dia dos estudantes no terreiro, como também para perceber se havia alguma interação construída ao longo dos anos entre os estudantes, os seus ancestrais e a divindade. Ficou evidenciado, pelos depoimentos de S-1 e S-3 que Exu tem prestigio e é venerado no mesmo patamar dos outros Orixás, chegando a ser tratado com mais destaque dentro do "barracão". Não obstante, S-4 ao descrever que Exu só quer o que é seu de direito, propõe, de forma objetiva, que é preciso "agradá-lo" pois Exu não pede muito. Foi fácil perceber, que em alguns momentos, houve confusão na identificação de Exu, seja o "Exu Coroado" e o "Exu Batizado", conforme explicou a Ialorixá Elizabeth de Oxum Opará. Para alguns sujeitos, como S-4, Exu tem ligação com sua ancestralidade - mãe e avô - portanto, contempla a continuidade.

Inicialmente, a proposta da pesquisa bibliográfica era de fazer com que os estudantes tivessem contato com novas visões sobre o culto aos Orixás, principalmente aquelas trazidas pelo método científico. De certa forma, podemos dizer que os alunos tiveram êxito, pois as seleções feitas por eles englobam muito bem a problemática. 
Como ferramenta de busca dos textos científicos usamos o Google Acadêmico, por ser um ambiente que muitos já utilizam durante as aulas de ciências da natureza/química, por exemplo. Nesse sentido, os alunos foram divididos em duplas para que apresentassem as conclusões e fizessem comentários sobre o artigo escolhido por eles. Observamos que os estudantes foram rigorosos na seleção e encontram, no período entre 2014 e 2020, vários argumentos que permitem refletir sobre a necessidade de resistir as investidas do cristianismo, seja católico e ou neopentecostal. As duplas e os artigos selecionados foram assim definidos:

- Dupla 01: S-1 (Babalorixá) e S-3 (Ekedi) - artigo de FERREIRA DIAS (2019), com o título "Chuta que é macumba": o percurso histórico-legal da perseguição às religiões afrobrasileiras". O texto traz um tema polêmico dentro do culto aos Orixás, que é o sacrifício de animais. Aponta também o termo "macumba", que para S-1 e S-2 é algo pejorativo e denigre a imagem dos praticantes. Portanto, uma discussão bastante pertinente pela problemática vivida na escola de EMTI;

- Dupla 02: S-2 (Ogã) e S-6 (Médium "Rodante") - artigo de CAPUTO (2018), cujo título é "Reparar miúdo, narrar kékeré-notas de fotoetnopoética com crianças de terreiros". O texto foi escolhido pelos estudantes, pois aborda uma narrativa que viveram e vivenciaram, ou seja, a infância nos terreiros.

- Dupla 03: S-4 (Médium "Rodante") e S-5 (Ogã) - artigo de Mourão (2010), "Esculturas da Umbanda: a outra arte sacra brasileira“. A justificativa apresentada por S-4 e S-6 para a escolha do tema foi o formato das esculturas, que para eles muitas vezes contribuem para que outras pessoas tenham uma impressão distorcida de Exu.

Estimulamos a oralidade dos estudantes, pois acreditamos que as falas desses atores devem ser preservadas, por se tratarem de importantes "documentos" de uma tradição transmitida, basicamente, por gestos, danças, cantigas, atitudes e com um vocabulário que precisa ser mais estudado nas academias. Contudo, tem pouca gente pesquisando sobre povos de terreiro e quase ninguém sobre terreiros sergipanos.

O aprender a conhecer e o aprender a conviver, abordagens trabalhadas pelo ICE (2010, p.12), passam a ser estimuladas com a prática da oralidade. Os diferentes grupos que compõem a comunidade escolar, através desta atitude, podem se pronunciar e até utilizar o seu vocabulário para legitimar a sua atuação no meio social.

Vários pesquisadores justificam a oralidade como importante ferramenta de pesquisa, inclusive defendendo a sua inserção. Fares (2010, p. 255), por exemplo, conclui que os "textos de tradição oral e popular são frequentes, tanto nos circuitos letrados, como no cotidiano de cada um de nós, seja na forma de conto, provérbio, máxima, dito popular, trova, cordel e etc.”. Mas, 


\section{Revista Docência e Cibercultura}

sabemos que abordar a oralidade em pesquisas traz alguns questionamentos referentes à validação dos métodos, por exemplo.

Gil (1999, p. 32), aponta que a maior parte das metodologias depende da narrativa, do relato, das experiências dos (as) participantes e Fares (2010, p.265-266) expõe a necessidade de que as poéticas orais sejam parte dos saberes a serem ensinados:

[...] desqualificar este objeto é desconsiderá-lo como texto fundador, a origem de todos os outros [...]. As poéticas orais fazem parte do universo cultural dos discentes, sobretudo os moradores da zona rural do Brasil, das zonas periféricas das grandes cidades, e os que (con) viveram nesses territórios ou com seus habitantes. Trazer esta realidade para o sistema de ensino, estabelecer relações de trocas simbólicas, é um dos sentidos da educação (FARES, 2010, p. 265-266).

E quando Fares (2010, p. 267) concluí que trazer a realidade dos discentes para o campo da escola, através da oralidade, é dar sentido a educação, contribuiu para a abordagem dos quatro pilares da educação do EMTI. Portanto, trabalhar com a oralidade implica em assumir as narrativas dos atores envolvidos na comunidade escolar e dar sentido as suas trocas de “informações", além de buscar captar os processos de conservação e resistência da cultura das comunidades-terreiros. Para Caputo (2012, p. 58), a transmissão de saberes é mais evidente quando se trata da educação em terreiros. Dessa forma, ao reconhecerem a importância da comunicação oral e sua influência sobre nossas vidas, diferentes pesquisadores reforçam a pratica da multiculturalidade (FAVERO, 2010, p. 45). E, por fim, estimular a oralidade implica em uma forma de sobrevivência, que se torna presente nas narrativas, nos pontos, nas mitologias das entidades, que são marcas identitárias para esses sujeitos Caputo (2012, p. 123).

A apresentação do filme "Besouro" consolidou alguns aspectos sobre a figura de Exu, inclusive aquela associada a resistência do povo negro e escravizado, seja com a prática do culto afrobrasileiro ou pela "arte marcial da capoeira". Abriu-se um campo enorme de possibilidades de trabalhar com a dinâmica dos povos de terreiro, principalmente, na comunidade da escola que foi construída a partir de um quilombo e de engenhos de açúcar. Exu é isso, continuidade.

\section{CONSIDERAÇÕES FINAIS}

As narrativas dos aprendizes, mesmo que de forma resumida, ao responderem as questões "a", "b" e "c" acabaram por impulsionar a oralidade do grupo. Foi possível perceber que as vivências dos indivíduos são carregadas de significados, símbolos, saberes/conhecimentos e que são trazidos de relações de parentesco e de resistência. "Tranca Rua", para alguns. é mais 
do que uma divindade do Candomblé ou da Umbanda, é algo que faz parte de suas rotinas e que transmite força e sabedoria. É como se a divindade/entidade fizesse parte da família.

Partindo deste contexto animador é preciso repensar o papel que devemos desempenhar na escola contemporânea, se optarmos por ignorar esses sujeitos e deixarmos de propor discussões que fazem parte de seus cotidianos, correremos o risco de isolarmos mais ainda estes seres humanos, que muitas vezes tem na escola o ambiente de convivência, que pode não ser ideal, mas que possibilita ao praticante do culto afro-brasileiro de ser inserido, observado e sair do ostracismo.

A pesquisa bibliográfica abriu um novo campo de possibilidades, pois os estudantes tiveram contato com narrativas que até então passavam despercebidas. A escolha que eles fizeram dos artigos a serem trabalhados nos encontros, demostrou que o campo para aprendizado é grande e que eles precisam se apropriar deste conhecimento para construírem argumentos, seja para contestar ou concordar com as narrativas dos grupos neopentecostais da escola ou de qualquer outro lugar. Resistir as investidas dos opressores e preservar os ensinamentos dos antepassados é uma questão de identidade.

Cada um conhece, interpreta e aceita Exu e "Tranca Rua" de um jeito diferente, mas a essência é a mesma: resistir e prosseguir. Em nossa vivencia como pesquisadores, "Tranca Rua” é visto como membro da família, ele aconselha, cobra, faz e desfaz. Para nós "Tranca Rua” é sim um amigo leal. Não é melhor ou pior do que os outros, ele é aquilo que trazemos conosco de nossas relações sociais, culturais e que ao longo do tempo se transformou em algo único e especial.

Tantas coisas vivemos com "Tranca Rua”, que dizem já cabem em um livro. Quando resolvemos levar essa divindade/entidade para a escola pública de um interior nordestino, que o catolicismo impera e o neopentecostalismo tenta tomar espaço, não pensamos em entrar nessa disputa. Aliás, essa disputa não nos interessa. Nós queremos respeito, para manter o direito constitucional de praticar o culto que nos completa. "Tranca Rua" diz: "ser livre é a questão".

Após ouvir atentamente os alunos - as histórias contadas por eles e suas relações com os Orixás e os povos dos terreiros - fomos convidados a explicar o motivo de ter escolhido "Tranca Rua" para "confrontar" os praticantes do "Clube da Bíblia". Explicamos que "Tranca Rua" simboliza muito no culto afro-brasileiro e Exu também, mas que "Tranca Rua" tem sido atacado e caluniado a décadas, portanto é preciso se opor ao posicionamento hegemônico e promover reflexões, mesmo na escola.

"Tranca Rua", por muito tempo foi meu único amigo. Em meus castigos de infância, que meu pai insistia em aplicar, quando retornava do "apagão" da incorporação, era ele que estava em pé junto com "Tuninho" (um Mirim). E, quando "Tuninho" me colocava em alguma 
"enrascada" era "Tranca Rua" que ficava até o fim do castigo, em pé na minha frente. Eu dormia, pois tinha castigo que durava alguns dias, mas quando acordava lá estava ele. Para mim nunca foi punição, pois ria e conversava normalmente. Às vezes, dormia chorando e acordava com ele parado a me olhar. Nunca tive medo, apesar de não ver seu rosto. Eu tinha uns oito anos, mais ou menos (eles começaram a me visitar antes dos setes anos, pois já estavam na festa de aniversário), quando meu tio disse que eu era "maluco", que tinha "merda na cabeça e miolo no botão" e que meu pai devia me levar para fazer exames e me internar, pois cada dia eu piorava mais, foi "Tranca Rua" quem disse para não me preocupar, pois não era nada: "somos nós, que eles não entendem".

Cresci sendo desprezado por alguns, que insistiam em dizer que eu era como um "burro empacador", pois "Tuninho" quando se aproximava me fazia contrariar meus pais. Com o tempo, eles passaram a me respeitar e tentar entender o que vivia.

Quando "Tranca Rua" avisou que havia sumido uma quantia de dinheiro da casa de meu tio, que tinha sido um amigo de meu primo o responsável e que estava escondido em um "buraco" no tijolo amarelo (que meu tio havia pintado com um resto de tinta), eles ficaram intrigados e perguntavam como eu sabia do tijolo amarelo? Sim lá estava o dinheiro, porém meu tio nunca disse nada. Mas, dessa data em diante, meu tio passou a me defender quando algo acontecia. "Tranca Rua" disse agora ele entende um pouco você. Até hoje, já se passaram mais de quarenta anos, e ele continua aqui. Amo "Tranca Rua", como amo meu pai.

E eu perguntei a Stela Guedes Caputo, em nossas conversas na Universidade do Estado do Rio de Janeiro, como explicar esse sentimento? Como amar alguém que você não abraça, não faz carinho ou interage como um ser humano? Como explicar esse sentimento para alguém que não é praticante do culto afro-brasileiro, um evangélico, por exemplo?

Sabemos que existem tantas e tantas histórias que podem ser contadas, seja do "Tranca Rua" ou de qualquer outra divindade/entidade do culto aos Orixás. E devem sim ser contadas, para serem legitimadas e aceitas como parte integrante da cultura dos terreiros e de seus povos. Esperamos que os estudantes participantes desta pesquisa contem suas histórias, sem vergonha, sem medo e que não precisem esconder seu culto para serem aceitos.

Dedicamos esta pesquisa aos estudantes da escola de EMTI, a minha filha e a todos os meninos e meninas do Candomblé e da Umbanda, que em algum momento se esconderam e tiveram que negar a sua crença para serem aceitos em algum grupo social.

\section{REFERÊNCIAS}


AMORIM, Marcos Paulo. Macumba no imaginário brasileiro: a construção de uma palavra. http://www. fespsp. org. br/seminario2013/artigos/IISeminarioPesquisa_MarcosAmorim. pdf. Acesso em, v. 15, p. 12, 2015.

BOGDAN, Robert; BIKLEN, SariKnopp. Investigação qualitativa em educação. [Trad.] ALVARES, M. J.; SANTOS, S. B.; BAPTISTA, T. M. Porto, Portugal: Porto Editora, LDA, 1994.

BASTIDE, Roger. Imagens do Nordeste místico em branco e preto. "Seção de livros" da empresa gráfica" O Cruzeiro", 1945.

CAPUTO, Stela Guedes. Educação nos terreiros: e como a escola se relaciona com crianças de candomblé/ Stela Guedes Caputo. - 1. Ed. - Rio de Janeiro: Pallas, 2012.

CAPUTO, Stela Guedes. REPARAR MIÚDO, NARRAR KÉKERÉ-NOTAS SOBRE NOSSA FOTOETNOPOÉTICA COM CRIANÇAS DE TERREIROS. Revista Teias, v. 19, n. 53, p. 36-63, 2018.

DA COSTA, P. Valdeli Carvalho. Alguns marcos na evolução histórica e situação atual de Exu na Umbanda do Rio Janeiro. Afro-Ásia, n. 13, 1980.

DE LIMA, Alessandro Luís Lopes. Exu: uma divindade africana no Brasil.

DE MORAIS, Mariana Ramos. Não chute, é macumba! Ou melhor, uma oferenda! - notas sobre as religiões afro-brasileiras no contexto da lei 10.639. Revista Educação e Políticas em Debate, v. 2, n. 1, 2013.

DE SOUZA CAMPOS, Ana Paula. A incorporação como arte: uma análise das festas de exu em terreiros de umbanda na zona oeste da cidade do Rio de Janeiro. PROA Revista De Antropologia E Arte, v. 1, n. 8, p. 8-31, 2018.

FARES, Josebel Akel. Oralidade e educação. Poéticas orais em sala de aula: relatos e retratos. In: Seminário Brasileiro de Poéticas Orais: vozes, performances, sonoridades I, 2010, Londrina. Anais. Londrina: Universidade Estadual de Londrina - UEL, 2010, p. 264 - 279.

FAVERO, Ivie. A Religião e as religiões africanas no Brasil, 2010. Texto utilizado no curso Presença Africano nas Matrizes Culturais Brasileiras, Secretaria Municipal de Educação de Santos. <https://www.egov.santos.sp.gov.br/ead/cursos/aplic/index.php?cod_curso=7> Acesso em: 14 de dez. de 2019

FERREIRA DIAS, J. "Chuta que é macumba": o percurso histórico-legal da perseguição às religiões afro-brasileiras. "Chuta que é macumba": o percurso histórico-legal da perseguição às religiões afro-brasileiras, n. 22, p. 39-62, 2019. 
FOUCAULT, Michel. Microfísica do Poder. [Trad.] MACHADO, R. Rio de Janeiro: Graal, 1979.

FOUCAULT, Michel. Em defesa da Sociedade: curso no Collége de France. [Trad.] GALVÃO, M. E. A. P. São Paulo: WMF Martins Fontes, 2005.

GEERTZ, Cliford. A interpretação das Culturas. Rio de Janeiro: Ed. LTC; 2008.

GIL, Antônio Carlos. Métodos e técnicas de pesquisa social. 5 ed. São Paulo: Atlas, p. 128138, 1999.

IMAGENS NO TERREIRO, As. ESCULTURAS DA UMBANDA: A OUTRA ARTE SACRA BRASILEIRA. Projeto Estudos comparados dos saberes e das artes nos circuitos da cultura popular Coordenação geral, p. 185.

MANUAL OPERACIONAL DO ICE: protagonismo juvenil suas vivências e práticas. Recife: ICE, 2010.

PRANDI, Reginaldo. Exu, de mensageiro a diabo. Sincretismo católico e demonização do orixá Exu. Revista USP, n. 50, p. 46-63, 2001.

RAMOS, Arthur. Aculturação Negra no Brasil. São Paulo; Rio de Janeiro; Recife; Porto Alegre: Companhia da Editora Nacional, 1942.

RAMOS, Arthur. O Negro brasileiro: etnografia religiosa. 3. Ed. São Paulo: Editora Nacional, 1951.

RAMOS, Arthur. O Negro na civilização brasileira. Rio de Janeiro: Livraria-Editora Casa do Estudante, 1971a. Col. Arthur Ramos. v. I.

ROHDE, Bruno Faria. Umbanda, uma Religião que não Nasceu: Breves Considerações sobre uma Tendência Dominante na Interpretação do Universo Umbandista. REVER: Revista de Estudos da Religião, v. 9, 2009.

RODRIGUES, Raymundo Nina; VELHO, Yvonne Maggie Alves; FRY, Peter. O animismo fetichista dos negros baianos. Ministério da Cultura, Fundação Biblioteca Nacional, 2006.

OLIVEIRA, José Henrique Motta de. Entre a Macumba e o Espiritismo: uma análise do discurso dos intelectuais de umbanda durante o Estado Novo. CAOS-Revista Eletrônica de Ciências Sociais, nº, p. 60-85, 2009.

Este é um artigo de acesso aberto distribuído sob os termos da Licença Creative Commons Atribuição Não Comercial-Compartilha Igual (CC BY-NC- 4.0), que permite uso, distribuição e reprodução para fins não comerciais, com a citação dos autores e da fonte original e sob a mesma licença. 